\title{
Über 4-Azoxyphtalsäure
}

Von

\section{Georg Sachs}

Aus dem I. Chemischen Laboratorium der $\mathrm{k}$. $\mathrm{k}$. Universität in Wien

(Vorgelegt in der Sitzung am 2. Dezember 1915)

O. Miller ${ }^{1}$ erhielt bei der Verseifung des 4-Nitrophtalsäurediäthylesters, den er zur Trennung der beiden beim Nitrieren der Phtalsäure entstehenden Mononitroprodukte darstellte, unter Anwendung von alkoholischem Kali in geringer Menge gelbe Produkte, welche der erzielten Säure ein einheitliches Aussehen raubten. Ich erhielt gelegentlich einer Wiederholung dieses Versuches offenbar durch $z u$ energisches Einwirken des alkoholischen Kalis so viel von diesem Körper, daß ich ihn nährer untersuchen konnte.

Nach der Verseifung blieb beim Abdestillieren des Alkohols eine fast schwarz gefärbte Masse zurück, die, mit Wasser aufgenommen und von dem wenigen Ungelösten durch Filtration getrennt, auf Zusatz von Salzsäure einen rötlichen bis braunen Körper ausschied, der im Anschützapparat bis $220^{\circ}$ nicht schmolz. Durch Umkrystallisieren aus salzsäurehaltigem Wasser wurden bei ungefähr $300^{\circ}$ schmelzende Fraktionen gewonnen. Sie waren kein Salz. Dies ging aus quantitativen Bestimmungen der Sulfatasche und des Ammoniaks hervor, sowie daraus, daß abermaliges Umkrystallisieren aus salz-

1 Lieb. Ann., 208, 228 (1880). 
säurehaltigem Wasser den Schmelzpunkt nicht wesentlich änderte.

Zur Reinigung eignet sich am besten Umkrystallisieren aus reinem oder salzsäurehaltigem Wasser; auch ein Gemisch von Alkohol und Benzol ist brauchbar. Aus der Lösung in Kalilauge erhält man durch Zusatz von Salzsäure leicht aschehaltige, bis $360^{\circ}$ nicht schmelzende Fällungen (offenbar saure Salze), aus denen man den ursprünglichen Stoff durch Verreiben mit Salzsäure erhalten kann. Umkrystallisieren aus Alkohol führt (wahrscheinlich infolge teilweiser Veresterung) nicht selten $z u$ bei ungefähr $160^{\circ}$ schmelzenden Produkten, die durch Kochen mit Kalilauge und Fällen mit Salzsäure auf einen um $220^{\circ}$ liegenden Schmelzpunkt gebracht werden können.

Die Substanz hatte kein deutlich krystallinisches Aussehen. Sie war lachsfarben (auch nach Behandlung mit Tierkohle), in kaltem Wasser schwer, in heißem leichter, in Alkohol leicht löslich. Aus der wässerigen Lösung geht sie nicht leicht in Äther.

Der Schmelzpunkt hängt in ganz ungewöhnlichem Maß von schwer beherrschbaren Zufälligkeiten ab. Es scheint ein doppelter Schmelzpunkt aufzutreten, einer bei etwa $22^{\circ}$ (in der Regel aber recht unscharf und tiefer) und einer in der Gegend von $300^{\circ}$ (mehr oder weniger unscharf zwischen $280^{\circ}$ und $310^{\circ}$ ); ersterer ist mit Dunkelfärbung und geringer Gasentwicklung verbunden, letzterer mit starker Gasentwicklung, so daß dünnwandige, zugeschmolzene Kapillaren explodieren. Aber nur selten beobachtet man teilweises Schmelzen bei 220 bis $230^{\circ}$, nachfolgendes Festerwerden und völlige Verflüssigung bei höherer Temperatur. Völlige Verflüssigung beim unteren Schmelzpunkt bekommt man am leichtesten (aber auch nicht regelmäßig) beim Eintauchen in ein auf $200^{\circ}$ vorgewärmtes $\mathrm{Bad}$ und raschem Erhitzen, selten beim langsamen Erhitzen. Aber es kommt auch häufig vor, daf hei anscheinend gleich ausgeführten Bestimmungen der untere Schmelzpunkt völlig ausbleibt.

Die Analyse zeigte, daß 4-Azoxyphtalsäure vorlag. 
I. $0.2124 \mathrm{~g}$ (bei $100^{\circ}$ getrocknet) gaben $0.3969 \mathrm{~g} \mathrm{CO}_{2}, 0.0496 g \mathrm{H}_{2} \mathrm{O}$.

II. $0 \cdot 1022 g$ gaben $12 \cdot 68 \mathrm{~cm}^{3} \mathrm{~N}_{2}\left(14^{\circ}, 745 \mathrm{~mm}\right)$.

Gef. C $50 \cdot 97, \mathrm{H} 2 \cdot 61$, N $7 \cdot 70$; ber. für $\mathrm{C}_{16} \mathrm{H}_{10} \mathrm{O}_{9} \mathrm{~N}_{2}, \mathrm{C} 51 \cdot 33, \mathrm{H} 2 \cdot 70$, N $7 \cdot 49 \%$.

Zur Darstellung der 4-Azoxyphtalsäure kann man auch 1 Gewichtsteil freier 4-Nitrophtalsäure mit einer Lösung von 3 Gewichtsteilen Ätzkali in $8 \mathrm{~cm}^{3}$ Alkohol 10 Stunden am Wasserbad erhitzen. Bei zu niedriger Temperatur tritt die Reaktion nicht ein. Nach dem Verdampfen des aldehydhältigen Alkohols und Auflösen in Wasser erhält man durch Umkrystallisieren aus Wasser und nötigenfalls durch Verreiben aschehältiger Fraktionen mit Salzsäure etwa $0 \cdot 4$ Gewichtsteile Azoxysäure. Sie zeigte das gleiche Verhalten beim Erhitzen wie die früher beschriebene Säure und gab, was für die Identität beweisender ist, denselben Tetramethylester.

\section{4-Azoxyphtalsäuretetramethylester.}

Die Säure wurde mit der zwölffachen Gewichtsmenge Methylalkohol übergossen, der Methylalkohol in der Hitze mit Chlorwasserstoff gesättigt, dann noch unter weiterem Durchleiten 2 bis 3 Stunden gekocht. Der Ester krystallisierte allmählich in sehr guter Ausbeute fast rein aus und wurde durch Fällung aus Benzol mit Petroläther, wobei unreinere Proben sich bisweilen zuerst ölig abschieden, auf den Schmelzpunkt 103 bis $104^{\circ}$ gebracht.

Ads Neutralester erwies sich der erhaltene Körper durch seine Unlöslichkeit in Ammoniak. Er war orange gefärbt, in Benzol, Essigäther und Aceton sehr leicht löslich, leicht löslich in Methyl- und Äthylalkohol und sehr schwer löslich in Petroläther.

$0 \cdot 1798 \mathrm{~g}$ (valisumtrocken) gaben nach Z Zeise $10 \cdot 3943 \mathrm{~g} \mathrm{AgJ}$.

$\mathrm{OCH}_{3}$ gef. $28 \cdot 97$; ber. für $\mathrm{C}_{20} \mathrm{H}_{18} \mathrm{O}_{9} \mathrm{~N}_{2}=\mathrm{C}_{16} \mathrm{H}_{6} \mathrm{O}_{5} \mathrm{~N}_{2}\left(\mathrm{OCH}_{3}\right)_{1} 28 \cdot 84_{60}^{0}$.

Der Versuch einer Halbverseifung des Neutralesters mit methylalkoholischer Kalilauge verlief nicht glatt. Neben unverändertem Neutralester und Schmieren wurden Krystallisa- 
tionen mit Schmelzpunkten zwischen 140 und $170^{\circ}$ erhalten, die zum Teil miteinander Schmelzpunktserniedrigungen gaben und beim Umkrystallisieren oft in schwer krystallisierende Sirupe übergingen.

Herrn Prof. R. Wegscheider gestatte ich mir für die Unterstützung, die er der Arbeit angedeihen ließ, bestens zu danken. 